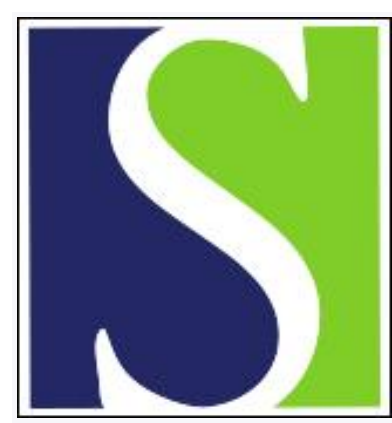

Scand J Work Environ Health 1986;12(4):323-326

https://doi.org/10.5271/sjweh.2136

Issue date: Aug 1986

Impulsiveness of vibration as an additional factor in the hazards associated with hand-arm vibration.

by Starck J, Pyykko I

This article in PubMed: www.ncbi.nlm.nih.gov/pubmed/3775316

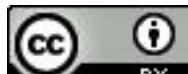




\title{
Impulsiveness of vibration as an additional factor in the hazards associated with hand-arm vibration
}

\author{
by Jukka Starck, PhD, IImari Pyykkö, MD ${ }^{1}$
}

\begin{abstract}
STARCK J, PYYKKÖ I. Impulsiveness of vibration as an additional factor in the hazards associated with hand-arm vibration. Srand $J$ Work Environ Health 12 (1986) 323-326. Impulsiveness is defined as the difference between peak and root-mean-square signals. As the difference varies in time, the cumulative distribution function has been used to describe the probability of achieving a certain value of impulsiveness. To make numerical comparison of different vibration signals possible, an impulse index has been selected from the cumulative distribution function. Symptoms of vibration-induced white finger were observed and compared to those expected on the basis of measurements taken according to guidelines of the International Organization for Standardization (ISO). Agreement was found for chain-saw vibration. In the case of pedestal grinding, the ISO draft underestimated the hazardous effects of vibration. Stone workers using pneumatic hammers were exposed to highly impulsive but asymmetrical vibration. The corresponding assymmetry was not, however, observed between the symptoms of the left and right hands, a finding which indicates that coupling between the tool and the hand is important for impulse vibration. The results suggest that the impulse character of vibration increases the risk of vibration-induced pathology. The analysis of high-impulse acceleration peaks obtained by the method presented in this study could provide additional data necessary to improve risk assessment.
\end{abstract}

Key terms: asymmetrical vibration, chain saw, impulse vibration, pedestal grinding, pneumatic hammer, risk assessment.

Measurement of root-mean-square (rms) acceleration does not take into consideration short, high peak values of the vibratory signal, which may be more hazardous in the development of the vibration syndrome than is generally thought $(1,9)$.

The purpose of the present report is to measure and analyze the high peak level of impulse vibration from different tools and occupations and to relate the results to the observed prevalence and latency data from exposed workers.

\section{Subjects and methods}

\section{Definition of impulsiveness}

The primary quantity used to describe the magnitude of vibration is rms acceleration. If the vibration signal contains impulses, the time-averaged energy level $\left(L_{\mathrm{rms}}\right)$ remains low in comparison with the peak level of individual impulses $\left(L_{\text {peak }}\right)$. The shorter the impulse, the greater the difference between the peak and rms level. This phenomenon led to the assessment of impulsiveness on the basis of the difference between the peak and rms signals in decibels $(4,7)$. The difference, called $I$, also known as the crest factor of the signal, can be expressed as

$$
I=L_{\text {peak }}-L_{\text {rms }} \text {. }
$$

The definition is suitable for the continuous analysis of randomly varying signals. The function computed

\footnotetext{
1 Institute of Occupational Health, Helsinki, Finland.

Reprint requests to: Dr J Starck, Institute of Occupational Health, Laajaniityntie 1, SF-01620 Vantaa, Finland.
}

is the cumulative distribution function (CDF) for difference I (6). From the cumulative distribution function the impulse index $I_{I}$ is selected to compare the impulsiveness of different vibration signals. This impulse index indicates the difference between peak and rms signals in decibels that corresponds to the 1 percentile value.

\section{Subjects}

This study comprised three different groups of workers exposed to vibration from different types of tools. A longitudinal study among professional forest workers was conducted from $1972(\mathrm{~N}=118)$ to $1980(\mathrm{~N}=$ 217) on persons who had used chain saws for at least three consecutive years for a minimum of $500 \mathrm{~h}$ a year (5). Sixteen professional stone workers who used pneumatic hammers were examined in a cross-sectional study, as well as 12 pedestal grinders $(6,8)$.

\section{Tools}

The vibration measurements comprised three different generations of chain saws. The first-generation chain saw was a Homelite Zip manufactured in 1958. It represented the chain saws used in the 1960s and was not supplied with any antivibration elements. In the late 1960s the first so-called antivibrating chain saws replaced the first-generation saws. A Partner R22 was selected to represent this second generation. The vibration of chain saws was reduced further in the 1970s, and a Raket R420 was selected to represent this generation. The operation time increased from $2 \mathrm{~h}$ to about $5 \mathrm{~h}$ daily during the follow-up period (5).

The pneumatic hammer was used by stone workers. 
(a)
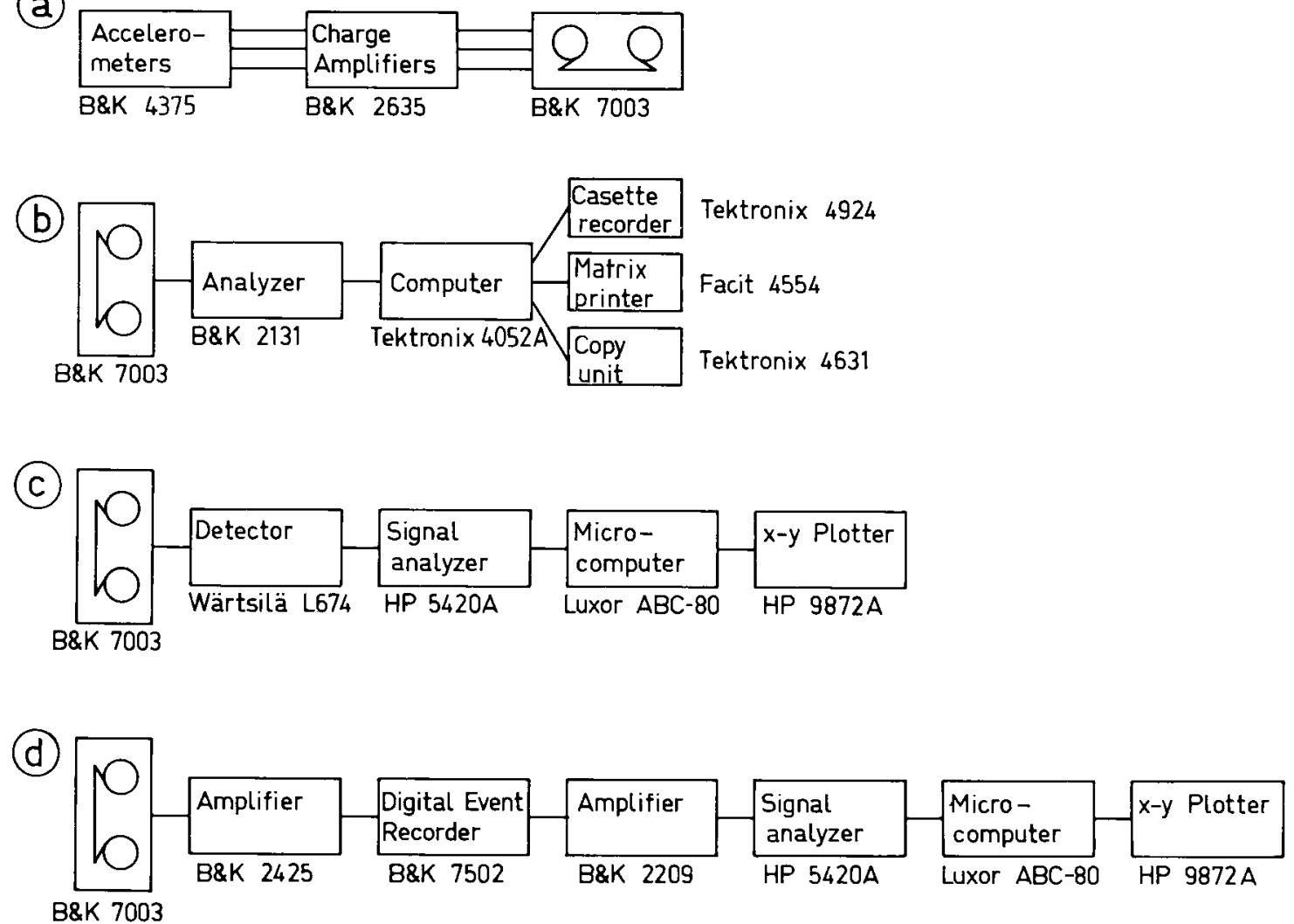

Figure 1. Block diagram of the equipment used in the measurements and laboratory analyses in the field (a); in the laboratory, according to ISO/DIS 5349.2 (3) (b); in the laboratory, for the analyses of impulsiveness (c); and in the laboratory, for the analyses of time history (d). (B \& K = Brüel \& Kjaer, HP = Hewlett Packard)

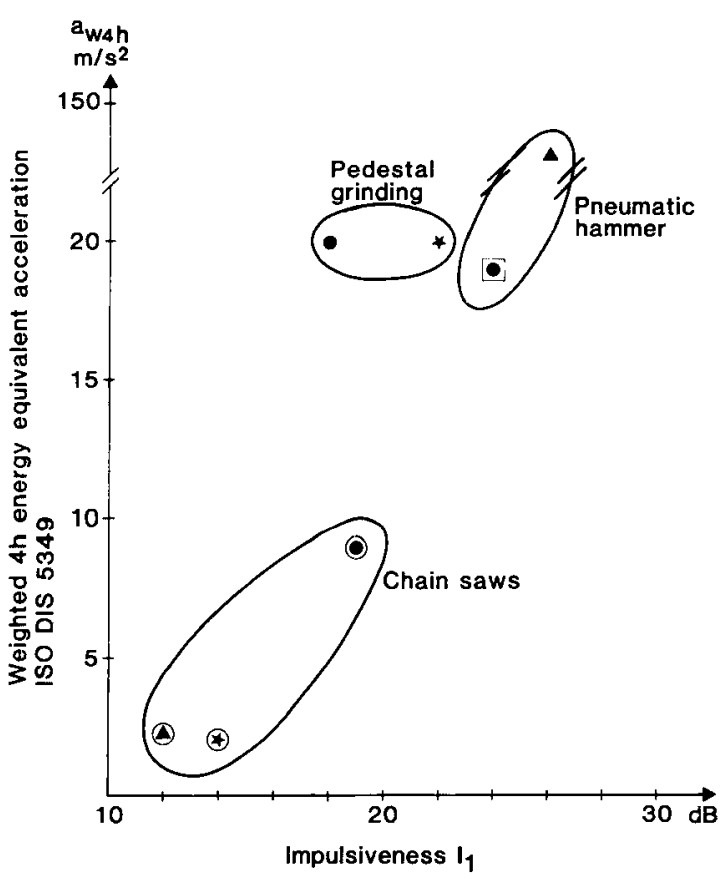

The left hand was in contact with the chisel head, and the right hand with the barrel.

Pedestal grinding was used in a foundry for cleaning small castings by hand. The vibration of two different types of grinding wheels was measured, one being made of corundum and the other of zirconium corundum. The corundum wheel had not caused vibration-induced white finger (VWF) in any of the grinders, whereas the zirconium corundum wheel proved to be very hazardous in that all the workers had contracted the syndrome within one year of changing to this wheel (8).

\section{Equipment for the recordings and analyses}

A lightweight accelerometer was attached to a mechanical filter, which in turn was mounted rigidly by a screw

Figure 2. Weighted 4-h energy equivalent acceleration $\left(a_{w 4}\right)$ and impulsiveness $\left(I_{1}\right)$ of vibration for pedestal grinding with a corundum wheel (circle), pedestal grinding with a zirkonium corundum wheel (star), a Homelite ZiP 1958 chain saw (encircled circle), a Partner R22 1972 chain saw (encircled star), a Raket R 4201982 chain saw (encircled triangle), the chisel head of a pneumatic hammer (triangle), and the barrel of a pneumatic hammer (circle in a square). 

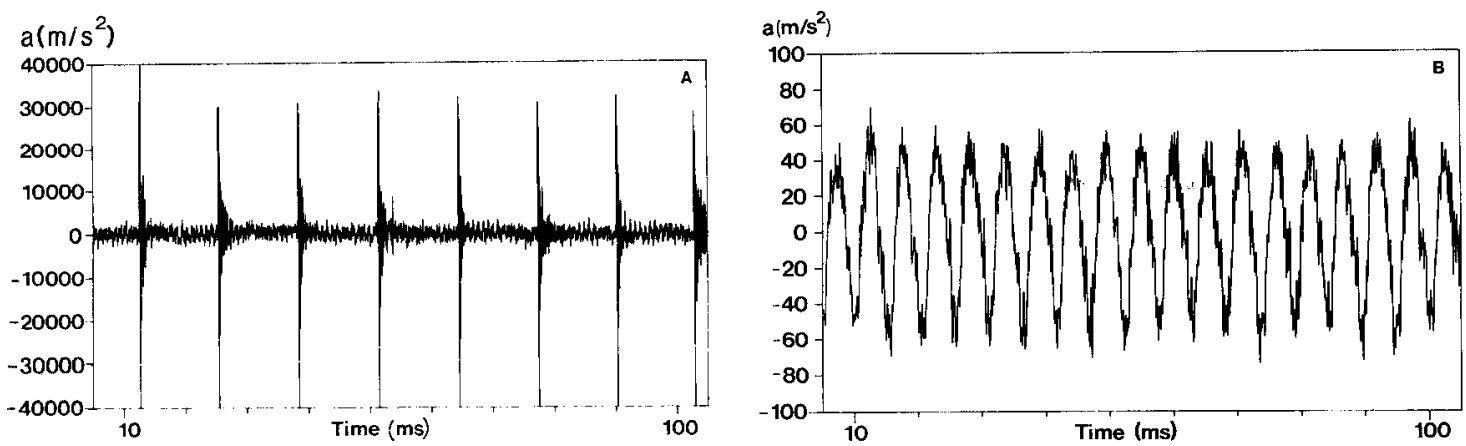

Figure 3. Transient recordings of vibration for the chisel head of a pneumatic hammer (A) and the most up-to-date chain saw (B).

Table 1. Expected latency period and prevalence of vibration-induced white finger (VWF) assessed according to ISO/DIS 5349.2 (3) in comparison with the observed latency and prevalence. $\left(a_{w 4 h}=\right.$ frequency-weighted 4-h energy equivalent acceleration, $l_{1}=$ impulse index for the percentage value of 1 )

\begin{tabular}{|c|c|c|c|c|c|c|}
\hline \multirow{3}{*}{ Tool $^{\mathbf{a}}$} & \multirow{3}{*}{$\begin{array}{l}a_{w 4 h} \\
\left(\mathrm{~m} / \mathrm{s}^{2}\right)\end{array}$} & \multirow{3}{*}{$\stackrel{l}{l_{1}}$} & \multicolumn{4}{|c|}{ VWF } \\
\hline & & & \multicolumn{2}{|c|}{$\begin{array}{l}\text { Expected latency } \\
\text { period (years) }\end{array}$} & \multirow{2}{*}{$\begin{array}{l}\text { Observed } \\
\text { latency } \\
\text { period } \\
\text { (years) }\end{array}$} & \multirow{2}{*}{$\begin{array}{c}\text { Observed } \\
\text { prevalence } \\
(\%)\end{array}$} \\
\hline & & & $\begin{array}{c}\text { Prevalence } \\
10 \%\end{array}$ & $\begin{array}{l}\text { Prevalence } \\
\quad 50 \%\end{array}$ & & \\
\hline \multicolumn{7}{|l|}{ Pedestal grinding } \\
\hline $\begin{array}{l}\text { Corundum wheel } \\
\text { Zirconium wheel }\end{array}$ & $\begin{array}{l}20 \\
20\end{array}$ & $\begin{array}{l}18 \\
21\end{array}$ & $\begin{array}{l}1.3 \\
1.3\end{array}$ & $\begin{array}{l}3.2 \\
3.2\end{array}$ & $\begin{array}{l}>5 \\
<1\end{array}$ & $\begin{array}{c}\text { not known } \\
100\end{array}$ \\
\hline \multicolumn{7}{|l|}{ Chain saw } \\
\hline $\begin{array}{l}\text { Homelite ZIP } 1958 \\
\text { Partner R22 } 1972 \\
\text { Raket R420 } 1982\end{array}$ & $\begin{array}{l}9 \\
2 \\
2\end{array}$ & $\begin{array}{l}19 \\
14 \\
12\end{array}$ & $\begin{array}{r}3.3 \\
15.0 \\
13.7\end{array}$ & $\begin{array}{l}7.5 \\
33 \\
30.5\end{array}$ & $\begin{aligned} &<5 \\
&<10 \\
& \text { not known }\end{aligned}$ & $\begin{array}{r}40 \\
16 \\
<7\end{array}$ \\
\hline \multicolumn{7}{|l|}{ Pneumatic hammer } \\
\hline $\begin{array}{l}\text { Chisel head } \\
\text { Barrel }\end{array}$ & $\begin{array}{r}130 \\
19\end{array}$ & $\begin{array}{l}26 \\
22\end{array}$ & $\begin{array}{l}0.2 \\
1.6\end{array}$ & $\begin{array}{l}0.5 \\
3.5\end{array}$ & $\begin{array}{l}6 \\
9\end{array}$ & $\begin{array}{l}75 \\
50\end{array}$ \\
\hline
\end{tabular}

to the measuring point. Acceleration was recorded in the frequency range from $2 \mathrm{~Hz}$ to $10 \mathrm{kHz}$, and in this range the frequency response was linear within $1 \mathrm{~dB}$.

The total and frequency-weighted acceleration was calculated from the average one-third octave spectrum according to the guidelines of the International Organization for Standardization (ISO) (3). This spectrum was formed from 20 to 50 spectra, each time-averaged $0.5 \mathrm{~s}$ and sampled at intervals of $0.5 \mathrm{~s}$.

The probability distribution function was generated by a fast Fourier transform analyzer after rms and peak detectors were first employed. The cumulative distribution function was calculated by a microcomputer, which also showed the selected impulse index.

A detailed time history analysis was carried out with a transient recorder and a microcomputer for signals of 100 -ms duration, which were constructed by the joining of recurrent $10-\mathrm{ms}$ samples analyzed with a bandwidth of $12.8 \mathrm{kHz}$.

\section{Results}

The frequency-weighted 4-h equivalent acceleration and the impulsiveness of the vibration are presented for each tool in figure 2. The pneumatic hammer and, especially, the chisel head generated weighted-equivalent acceleration and impulsiveness. The corundum and zirconium corundum grinding wheels produced the same frequency-weighted acceleration, but the impulsiveness of the vibration generated by the zirconium corundum wheel was higher than that generated by the corundum wheel. Of the different chain saws, the oldest type of saw generated vibration with the highest weighted acceleration and impulsiveness. The most upto-date chain saw generated the lowest impulsiveness.

Transient analyses were performed in an attempt to find an explanation for these results.

The chisel head generated short peaks that occurred regularly at intervals of $12 \mathrm{~ms}$. The most up-to-date chain saw produced vibration with the least impulsiveness, and transient analysis showed that it contained no peaks.

\section{Discussion}

The risk assessment of VWF was done according to the ISO method. Both 10 and 50 percentiles were eval- 
uated. The expected values were compared with the observed ones for different tools. Agreement was found for the chain saws. In the case of pedestal grinding, the ISO guidelines underestimated the hazardous effects of the vibration. According to it the prevalence of VWF among the grinders should have required a weighted acceleration of about $55 \mathrm{~m} / \mathrm{s}^{2}$, but in this study it was about $20 \mathrm{~m} / \mathrm{s}^{2}$.

The stone workers using pneumatic hammers were exposed to highly impulsive vibration. Their left hand was in contact with the chisel head where the frequency-weighted 4-h acceleration was about seven times greater than in the barrel of the pneumatic hammer held by the right hand. A corresponding asymmetry in the symptoms was not observed (2). The finding suggests that nonlinear transmission from the vibrating tool to the wrist occurs when impulse vibration is being generated. In the case of chisel head vibration the explanation might be the short duration of the high peak values in the vibration signal.

\section{Conclusions}

The present results suggest that conventional methods of measuring vibration do not reveal all its hazardous characteristics. High impact components were observed in the tools regarded to be the most hazardous. An additional problem in the measurement of vibration for risk assessment purposes is related to the amplitude-dependent transmission of vibration within the body. The analysis of high-impulse acceleration by the method presented in this study could provide ad- ditional data necessary to improve the assessment of the risk involved in exposure to hazardous handtransmitted vibration.

\section{References}

1. Dart EE. Effects of high speed vibration tools in operators engaged in airplane industry. Occup Med 1 (1946) $515-550$.

2. Färkkilä M, Starck J, Hyvärinen J, Kurppa K. Vasospastic symptoms caused by asymmetrical vibration exposure of the upper extremities to a pneumatic hammer. Scand J Work Environ Health 4 (1978) 330-335.

3. International Organization for Standardization. Guidelines for the measurement and the assessment of human exposure to hand-transmitted vibration. Geneva 1984. (ISO/DIS 5349.2-1984).

4. Lahti T, Starck J. Industrial impulse noise measurements. Scand Audio (1980): suppl 12,61-69.

5. Pyykkö I, Korhonen O, Färkkilä M, Starck J, Aatola S. A longitudinal study of the vibration syndrome in Finnish forestry workers. In: Brammer AJ, Taylor W, ed. Vibration effects on the hand and arm in industry. John Wiley \& Sons, New York, NY 1982, pp 157-167.

6. Spiegel MR. Theory and problems of statistics. McGrawHill Book Company, New York, NY 1972, p 359. (Schaum's artline series).

7. Starck J. Characteristics of vibration, hand grip force, and hearing loss in vibration syndrome. University of Kuopio, Kuopio 1984. (Original reports 4/1984, natural sciences).

8. Starck J, Färkkilä M, Aatola S, Pyykkö I, Korhonen O. Vibration syndrome and vibration in pedestal grinding. Br J Ind Med 40 (1983) 426-433.

9. Taylor W, Pelmear PL, Pearson J. Raynaud's phenomenon in forestry chain saw operators. In: Taylor W, ed. The vibration syndrome. Academic Press, London 1974, pp 121-139. 